\title{
Central versus peripheral cardiovascular risk in metabolic syndrome
}

\author{
H. Edgell ${ }^{1}$, R. J. Petrella ${ }^{1,2}$, G. J. Hodges ${ }^{3}$ and J. K. Shoemaker ${ }^{1}{ }^{*}$ \\ ${ }^{1}$ Department of Kinesiology, University of Western Ontario, London, ON, Canada \\ ${ }^{2}$ Schulich School of Medicine, Family Medicine, University of Western Ontario, London, ON, Canada \\ ${ }^{3}$ Department of Kinesiology, University of Alabama, Tuscaloosa, AL, USA
}

\section{Edited by:}

Derek John Hausenloy, University

College London, UK

\section{Reviewed by:}

Mihaela M. Mocanu, University

College London, UK

Robert Boushel, University of

Copenhagen, Denmark

*Correspondence:

J. K. Shoemaker, Faculty of Health Sciences, University of Western

Ontario, Room 3110 Thames Hall, London, ON, Canada N6A 5B9.

e-mail:kshoemak@uwo.ca
Individuals with metabolic syndrome (MetS; i.e., three of five of the following risk factors (RFs): elevated blood pressure, waist circumference, triglycerides, blood glucose, or reduced HDL) are thought to be prone to serious cardiovascular disease and there is debate as to whether the disease begins in the peripheral vasculature or centrally. This study investigates hemodynamics, cardiac function/morphology, and mechanical properties of the central (heart, carotid artery) or peripheral [total peripheral resistance (TPR), forearm vascular bed] vasculature in individuals without (1-2 RFs: $n=28$ ), or with ( $\geq 3$ RFs: $n=46$ ) MetS. After adjustments for statin and blood pressure medication use, those with MetS had lower mitral valve E/A ratios ( $<3$ RFs: $1.24 \pm 0.07 ; \geq 3$ RFs: $1.01 \pm 0.04 ; P=0.025$ ), and higher TPR index ( $<3$ RFs: $48 \pm 2 \mathrm{mmHg} / \mathrm{L} / \mathrm{min} / \mathrm{m}^{2} ; \geq 3 \mathrm{RFs}: 53 \pm 2 \mathrm{mmHg} / \mathrm{L} / \mathrm{min} / \mathrm{m}^{2}$; $P=0.04)$. There were no differences in heart size, carotid artery measurements, cardiovagal baroreflex, pulse-wave velocity, stroke volume index, or cardiac output index due to MetS after adjustments for statin and blood pressure medication use. The use of statins was associated with increased inertia in the brachial vascular bed, increased $\mathrm{HbA} 1 \mathrm{c}$ and decreased LDL cholesterol. The independent use of anti-hypertensive medication was associated with decreased predicted $V_{\mathrm{O}_{2}}$ max, triglycerides, diastolic blood pressure, interventricular septum thickness, calculated left ventricle mass, left ventricle posterior wall thickness, and left ventricle pre-ejection period, but increased carotid stiffness, HDL cholesterol, and heart rate. These data imply that both a central cardiac effect and a peripheral effect of vascular resistance are expressed in MetS. These data also indicate that variance in between-group responses due to pharmacological treatments are important factors to consider in studying cardiovascular changes in these individuals.

Keywords: metabolic syndrome, hemodynamics, peripheral vasculature, echocardiography, carotid distensibility

\section{INTRODUCTION}

The metabolic syndrome (MetS) is known to increase the risk of more serious cardiovascular disease (Ingelsson et al., 2007). There is considerable interest in understanding the patterns of where and when the component metabolic risk factors (RFs) impact the cardiovascular system so that interventions can be more effectively targeted. In MetS there are opposing hypotheses as to where cardiovascular disease becomes initially established with some investigators suggesting that early vascular disease complications begin in peripheral vascular beds (Stokes and Granger, 2005; Struijker-Boudier et al., 2007) whereas others suggest a central origin (Tsuchikura et al., 2010) such as the heart or major elastic conduit arteries.

Ingelsson et al. (2007) reported that the probability of developing left ventricular hypertrophy and carotid artery stenosis was higher with MetS whereas the probability of developing peripheral artery disease was not significantly higher than a reference population. Similarly, in U.K. patients with Type 2 Diabetes, the presence of MetS was associated with a greater risk of macrovascular disease (i.e., myocardial infarction or stroke) without a change in microvascular complications (i.e., retinopathy, vitreous hemorrhage, or renal failure; Cull et al., 2007). On the other hand, Abdul-Ghani et al. (2006) found that MetS in Israeli Type 2 Diabetic patients was associated with a higher risk of microvascular complications (i.e., microalbuminuria, neuropathy, retinopathy, or leg ulcers). It may be that the pattern of cardiovascular complications is a function of the severity of MetS risk. Subcutaneous vessels $(\sim 250 \mu \mathrm{m})$ in people with MetS have been shown to have greater media thickness and cross-sectional area (Grassi et al., 2010). These vessels have also been shown to have impaired acetylcholine-induced relaxation compared to healthy control vessels; however, vascular stiffness was not different between groups (Grassi et al., 2010). In an animal model (obese Zucker rats), Frisbee (2005) observed reduced nitric oxide bioavailability in skeletal muscle microvasculature. Kraemer-Aguiar et al. (2008) found that people with MetS had smaller finger capillaries and lower functional capillary density. These observations describe the potential for greater peripheral resistance and perhaps microvascular complications in MetS. Similarly, these results suggest that peripheral vascular beds, such as the forearm, would express altered pulsatile 
vascular mechanics. Importantly, previous investigations typically investigated either central or peripheral cardiovascular repercussions of MetS but not in the same individuals and not as a function of risk profile.

Also, the impact of pharmacologic treatments for the risks associated with MetS, such as hypertension or hypercholesterolemia, may impact the magnitude of effect on the vascular outcome. Further, the duration, type, and intensity of treatment (i.e., to recommended therapeutic targets or not) can also influence the measured outcomes. Whereas some studies report data from medicated patients (Ingelsson et al., 2007; Della-Morte et al., 2010; Koivistoinen et al., 2010) others use unmedicated patients (Ferreira et al., 2005; Ghiadoni et al., 2008) and this may lead to the divergent data regarding vascular health in MetS patients.

Therefore, the first purpose of this investigation was to investigate concurrently the morphologic and mechanical characteristics of peripheral (i.e., limb) and central (i.e., heart and central arteries) cardiovascular tissues in individuals with a range of MetS RFs to test the hypothesis that vascular complications in metabolic disorders begin in peripheral vascular beds. Furthermore, medication status of these participants was considered as a complicating or confounding factor.

\section{MATERIALS AND METHODS}

All experimental procedures were approved by the Office of Research Ethics at the University of Western Ontario. Every participant was aware of his/her right to withdraw from the study at any time.

\section{PARTICIPANT RECRUITMENT AND ETHICS}

Participants were recruited from the public if they had at least one risk factor of MetS according to the National Cholesterol Education Program's Adult Treatment Panel III report (ATPIII; Grundy et al., 2004). Participants were defined as having MetS if they had three or more of the following RFs. RFs are: (1) waist circumference of $>102 \mathrm{~cm}$ for men and $>88 \mathrm{~cm}$ for women, (2) triglycerides of $\geq 150 \mathrm{mg} / \mathrm{dL}$ or $\geq 1.7 \mathrm{mmol} / \mathrm{L}$, (3) HDL cholesterol of $<40 \mathrm{mg} / \mathrm{dL}$ or $<1.0 \mathrm{mmol} / \mathrm{L}$ for men and $<50 \mathrm{mg} / \mathrm{dL}$ or $<1.3 \mathrm{mmol} / \mathrm{L}$ for women, (4) blood pressure of $\geq 130 / \geq 85 \mathrm{mmHg}$, and (5) fasting glucose of $\geq 110 \mathrm{mg} / \mathrm{dL}$ or $\geq 6.1 \mathrm{mmol} / \mathrm{L}$. Blood pressure and cholesterol were classified as a risk factor if the participant was medicated for related disorders. Types of medications used are found in Table 1. Seventy-two participants were Caucasian and two were of Middle-eastern descent. Participants were excluded if they failed a screening cardiac stress test, had Type 1 diabetes, had a history of major cardiovascular disease, had orthopedic or rheumatologic problems that impeded exercise, and/or started or changed cholesterol drug use within the previous 3 months. Participants arrived in the lab in a fasted state and had abstained from alcohol and caffeine for at least $12 \mathrm{~h}$.

\section{ANTHROPOMETRICS AND PLASMA HORMONES}

Predicted maximal aerobic capacity $\left(V_{\mathrm{O}_{2} \max }\right)$ was determined using a step test as described in Petrella et al. (2001). Height, weight, waist circumference, and supine manual blood pressure were measured by the same experimenter. Waist circumference
Table 1 | Cholesterol and anti-hypertensive medication profiles of participants.

\begin{tabular}{lll}
\hline Cholesterol medication & & $\boldsymbol{n}$ \\
& No drug & 49 \\
& Statin alone & 22 \\
& Statin with fenofibrates & 1 \\
& Statin with absorption & 3 \\
Anti-hypertensive medication & inhibitor & \\
& No drug & 34 \\
& Diuretic & 10 \\
& ACE-ARB & 22 \\
& $\alpha_{2}$-agonist & 1 \\
& Multiple drugs (calcium & 7 \\
& blocker use $n=4)$ &
\end{tabular}

ACE-ARB: either angiotensin converting enzyme inhibitors or angiotensin receptor blockers.

was measured above the iliac crest. Framingham risk score was determined using the National Cholesterol Education Program Risk Assessment Tool for Estimating 10-year Risk of Developing Hard CHD (Myocardial Infarction and Coronary Death; available at: http://hp2010.nhlbihin.net/atpiii/calculator.asp? usertype =prof\#moreinfo). Cholesterols, triglycerides, glucose, Hb1Ac, C-reactive protein, and insulin were measured commercially by Gamma-Dynacare Medical Laboratories (London, Canada). HOMA-IR was calculated by multiplying the plasma glucose concentration $(\mathrm{mmol} / \mathrm{L})$ with the plasma insulin concentration (pmol/L) and dividing by 155.

\section{SYSTEMIC HEMODYNAMICS}

Continuous blood pressure was measured using finger cuff plethysmography (Finometer, Finapres Medical Systems, Arnheim, Netherlands) and normalized to a manual blood pressure measurement to ensure accuracy of measurement. Heart rate was determined from an echocardiogram. Stroke volume was determined from the echocardiographic measurements using $Z$ derived formulas (de Simone et al., 1996) whereby end-diastolic volume $=4.5 \times$ left ventricle end-diastolic diameter ${ }^{2}$, end-systolic volume $=3.72 \times$ left ventricle end-systolic diameter ${ }^{2}$, and stroke volume $=$ end-diastolic volume - end-systolic volume. Cardiac output was calculated as stroke volume multiplied by heart rate. Cardiac output and stroke volume were normalized to body surface area. TPR index was calculated as mean arterial pressure (as determined from the manual blood pressure measurements) divided by normalized cardiac output.

\section{ULTRASOUND}

Ultrasound images of the carotid and brachial arteries were taken using a Vivid 7 Dimension system (10 MHz; GE Healthcare, Baie d'Urfe, Canada) with post-processing using EchoPAC Dimension software. Velocity waveforms of the mean blood flow velocity in each artery (Vivid 7 Dimension; 4.7 MHz), were sent through a spectrum analyzer (Multigon Neurovision Transcranial Doppler System Model 500M, Multigon Industries Inc., Yonkers, USA), and then sampled at $1 \mathrm{kHz}$ for online storage (Powerlab LabChart 
7.2). Brachial and carotid resistance were determined using the formulas: Flow $(\mathrm{mL} / \mathrm{min})=$ velocity $\times\left(\pi \times\right.$ radius $\left.^{2}\right) \times 60$, Resistance $=$ Mean Arterial Pressure/Flow. Brachial flow was normalized to arm volume. Forearm volume was assessed from the circumference at wrist $\left(c_{1}\right)$, circumference at the largest part of the forearm $\left(c_{2}\right)$, and the length between the two segments was measured such that Volume $=\left(\right.$ length $\left.\times c_{1}^{2}+\left(c_{1} \times c_{2}\right)+c_{2}^{2}\right) /(12 \pi)$. Carotid strain was calculated as (Systolic Diameter-Diastolic Diameter)/Diastolic Diameter. Carotid stiffness was calculated as $[\ln ($ Systolic Pressure/Diastolic Pressure]/Strain. Carotid distensibility was calculated as Strain/(Systolic Pressure-Diastolic Pressure). Carotid elasticity modulus was calculated as (Systolic Pressure-Diastolic Pressure)/Strain.

Echocardiography images were obtained using a Vivid $i$ system (GE Healthcare, Baie d'Urfe, Canada) with post-processing using EchoPAC Dimension software. Pulsed wave Doppler across the mitral valve was assessed and the passive filling of the ventricle ( $E$ wave) and the active filling ( $A$-wave) were measured. The mitral valve $E / A$ ratio (mitral valve inflow) and $E / E^{\prime}$ index (left ventricular relaxation) were used as non-invasive markers of left ventricular diastolic function (Nagueh et al., 2009).

\section{PULSE-WAVE VELOCITY}

Pulse-wave velocity (PWV) was determined from the lag time between the foot of the velocity signal from the carotid artery to either the foot of the pressure wave at the finger or the foot of the pressure wave at the toe (Piezo Electric Pulse Transducer, AD Instruments, Colorado Springs, USA). The distance between the carotid artery and the fingertip or the toe was measured and used to calculate the velocity of the pulse wave (distance/time).

All analog signals (electrocardiogram, ultrasound waveforms, blood pressure, toe-pulse pressure) were sampled at $1000 \mathrm{~Hz}$ (Powerlab; ADInstruments, Colorado Springs, USA) and recorded with LabChart 7.2.

\section{FOREARM VASCULAR BED MECHANICS}

The mechanical properties of the forearm vascular bed were quantified using a lumped Windkessel modeling approach. This approach, using brachial artery recordings of blood flow (ultrasound) and blood pressure (Finometer calculation) waveforms has been described in detail (Zamir et al., 2007). Briefly, concurrent blood pressure and flow velocity waveforms were measured at the brachial artery. The harmonics of the pressure waveform are modified using variables of compliance $(C)$, viscoelasticity $(K)$, and inertia $(L)$ to generate a reconstructed waveform that matches the actual measured flow waveform with minimal error. Forearm vascular bed compliance was normalized to arm volume. These values of $C, K$, and $L$ represent features that control the oscillatory component of pulsatile blood flow. Forearm vascular resistance $(\mathrm{R})$ is also calculated as a steady-state value over the average cardiac cycle.

\section{BARORECEPTOR SENSITIVITY}

At least $5 \mathrm{~min}$ of data including RR-interval and blood pressure were determined for a period of supine rest. These data were then entered into a MATLAB program to determine the cardiovagal baroreceptor sensitivity using the sequence method (Blaber et al., 1995; Parlow et al., 1995).

\section{STATISTICAL ANALYSIS}

There are two levels of analysis. First, the effect of risk factor accumulation was assessed by comparing data between participants with $<3$ RFs of MetS and participants with $\geq 3$ RFs of MetS using linear regression adjusted for cholesterol and blood pressure medications (SAS 9.2, SAS Institute Inc., Cary, USA; see Table 2). Second, the effects of anti-hypertensive medications or anti-cholesterol (statin) medications on the central and peripheral indices of cardiovascular status were also analyzed using linear regression adjusted for the alternate medication and risk factor group. Of the various outcomes assessed, those variables that exhibited a significant (or near significant) effect of medication are presented in Tables 3 and 4 . Data are presented as means \pm SD. $P$ values of $<0.05$ were considered statistically significant. SE values are provided in the Figure legends.

\section{RESULTS}

\section{EFFECT OF MetS RISK FACTOR PROFILE}

The differences between risk factor groups after statistical adjustment for the use of the anti-hypertensive and statin medications are found in Table 2 and 3 as well as Figures 1-4. In comparison to participants with $<3 \mathrm{RFs}$, participants with overt MetS were the same age $(P=0.98)$, but had higher body mass index (BMI; $P=0.01)$, lower HDL cholesterol $(P<0.0001)$, higher triglycerides $(P=0.002)$, higher $\operatorname{HbAlc}(P=0.02)$, higher insulin $(P=0.003)$, and higher HOMA-IR $(P=0.004)$. There was a tendency for lower diastolic blood pressure in the MetS group versus the group with $<3$ RFs ( $P=0.07$; Table 2$)$. However, the mean levels are very close and, for this reason, we attach no physiologic significance to this outcome.

Compared to individuals with $<3$ RFs, participants with MetS had similar calculated left ventricle mass $(P=0.49$; Figure 1A), interventricular septal wall thickness $(P=0.12$; Figure 1B), and left ventricular posterior wall thickness $(P=0.17$; Figure 1C). The $E / E^{\prime}$ ratio was not different between groups $(P=0.701$; data not shown). Participants with MetS had a lower mitral valve $E / A$ ratio ( $M V E / A$ ratio) compared to the low risk group $(P=0.03$; Effect Size $=0.7 ; \beta=0.89$; Figure $2 \mathrm{~A})$, but no difference in left ventricular pre-ejection period (LVPEP; $P=0.27$; Figure 2B). Also, these groups were not different in carotid artery strain $(P=0.34$; Figure 3A), stiffness $(P=0.40$; Figure 3B), distensibility $(P=0.75$; Figure $3 \mathrm{C})$, elasticity modulus $(P=0.23$; Figure 3D), cardiovagal baroreceptor sensitivity $(<3$ RFs: $12.6 \pm 6.3 \mathrm{~ms} / \mathrm{mmHg}$; $\geq 3$ RFs: $9.0 \pm 4.7 \mathrm{~ms} / \mathrm{mmHg} ; P=0.29$ ), carotid intima-media thickness ( $<3$ RFs: $0.62 \pm 0.14 \mathrm{~mm} ; \geq 3$ RFs: $0.69 \pm 0.18 \mathrm{~mm} ; P=0.13)$, stroke volume index $(P=0.19$; Figure 4A), or cardiac output index $(P=0.34$; Figure 4B). Compared to those with $<3$ RFs, participants with MetS had higher TPR index $(P=0.04$; Effect Size $=0.44 ; \beta=0.55$; Figure 4C).

There were no significant differences between groups for forearm vascular resistance $(P=0.41)$, compliance $(P=0.15)$, viscoelasticity $(P=0.37)$, or inertia $(P=0.99$; Table 3$)$. Similarly, there was no group effect for carotid vascular resistance $(<3$ 
Table 2 | Anthropometrics, risk factors of metabolic syndrome, and plasma hormones of participants.

\begin{tabular}{|c|c|c|c|c|c|c|}
\hline & $<3$ risk factors & $\geq 3$ risk factors & $\begin{array}{l}\text { Unadjusted } \\
P \text {-values }\end{array}$ & $\begin{array}{l}P \text {-values } \\
\text { adjusted } \\
\text { for statins }\end{array}$ & $\begin{array}{l}P \text {-values } \\
\text { adjusted for } \\
\text { anti-hypertension } \\
\text { medication }\end{array}$ & $\begin{array}{l}P \text {-values } \\
\text { adjusted for } \\
\text { both statins and } \\
\text { anti-hypertension } \\
\text { medication }\end{array}$ \\
\hline$n$ & 29 & 45 & - & - & - & - \\
\hline Number of RFs & $1.7 \pm 0.5$ & $3.6 \pm 0.8^{*}$ & $<0.0001$ & $<0.0001$ & $<0.0001$ & $<0.0001$ \\
\hline Age & $57.7 \pm 8.6$ & $59.0 \pm 7.0$ & 0.41 & 0.81 & 0.68 & 0.98 \\
\hline Predicted $V_{\mathrm{O}_{2}} \max (\mathrm{mL} / \mathrm{kg} / \mathrm{min})$ & $32.5 \pm 5.0$ & $29.1 \pm 6.1$ & 0.02 & 0.03 & 0.17 & 0.17 \\
\hline Framingham risk score (\%) & $4.5 \pm 4.2$ & $6.1 \pm 5.1$ & 0.16 & 0.37 & 0.13 & 0.26 \\
\hline $\mathrm{BMI}\left(\mathrm{kg} / \mathrm{m}^{2}\right)$ & $30.9 \pm 4.0$ & $34.6 \pm 5.4^{*}$ & 0.002 & 0.009 & 0.005 & 0.01 \\
\hline Waist circumference (cm) & $106.4 \pm 11.2$ & $112.0 \pm 11.5$ & 0.04 & 0.1 & 0.1 & 0.16 \\
\hline LDL cholesterol (mmol/L) & $3.0 \pm 0.8$ & $2.5 \pm 1.0$ & 0.046 & 0.26 & 0.25 & 0.58 \\
\hline $\mathrm{HbA} 1 \mathrm{c}(\%)$ & $5.66 \pm 0.31$ & $5.92 \pm 0.34^{*}$ & $<0.0001$ & 0.01 & 0.005 & 0.02 \\
\hline Insulin (pmol/L) & $67.5 \pm 35.0$ & $105.9 \pm 42.7^{*}$ & 0.001 & 0.003 & 0.001 & 0.003 \\
\hline HOMA-IR (pmol/L*mmol/L) & $2.4 \pm 1.3$ & $4.2 \pm 2.0^{*}$ & 0.0008 & 0.004 & 0.001 & 0.004 \\
\hline Heart rate $(\mathrm{bpm})$ & $64.9 \pm 10.5$ & $67.3 \pm 3.6$ & 0.32 & 0.38 & 0.78 & 0.85 \\
\hline Systolic pressure (mmHg) & $122.9 \pm 14.7$ & $126.7 \pm 12.6$ & 0.52 & 0.37 & 0.34 & 0.27 \\
\hline Diastolic pressure $(\mathrm{mmHg})$ & $74.4 \pm 8.5$ & $73.6 \pm 8.1$ & 0.29 & 0.23 & 0.07 & 0.07 \\
\hline C-reactive protein (mg/L) & $3.6 \pm 5.3$ & $3.2 \pm 3.3$ & 0.65 & 0.94 & 0.41 & 0.62 \\
\hline Current smoking (\#) & 1 & 3 & - & - & - & - \\
\hline
\end{tabular}

Values are mean $\pm S D$. HOMA-IR, homeostatic model assessment for insulin resistance; *indicates $P$-value of $<0.05$, adjusted for both statin use and anti-hypertension medication use.

Table 3 | Pulsatile mechanical properties of the forearm vascular bed.

\begin{tabular}{|c|c|c|c|c|c|c|}
\hline & $<3 \mathrm{RFs}$ & $\geq 3 \mathrm{RFs}$ & $\begin{array}{l}\text { Unadjusted } \\
P \text {-values }\end{array}$ & $\begin{array}{l}P \text {-values } \\
\text { adjusted } \\
\text { for statins }\end{array}$ & $\begin{array}{l}P \text {-values } \\
\text { adjusted for } \\
\text { anti-hypertension } \\
\text { medication }\end{array}$ & $\begin{array}{l}P \text {-values } \\
\text { adjusted for } \\
\text { both statins and } \\
\text { anti-hypertension } \\
\text { medication }\end{array}$ \\
\hline Resistance (mmHg/mL/min) & $6.6 \pm 4.9$ & $5.5 \pm 3.0$ & 0.23 & 0.50 & 0.23 & 0.41 \\
\hline Compliance $\left(\mathrm{mL} / \mathrm{mmHg} / \mathrm{cm}^{3}\right)$ & $6.60 e^{-6} \pm 4.11 e^{-6}$ & $5.80 e^{-6} \pm 2.82 e^{-6}$ & 0.33 & 0.20 & 0.21 & 0.15 \\
\hline Inertia $\left(\mathrm{mmHg} / \mathrm{mL} / \mathrm{min}^{2}\right)$ & $1.40 e^{-5} \pm 1.79 e^{-5}$ & $1.28 e^{-5} \pm 1.61 e^{-5}$ & 0.77 & 0.75 & 0.63 & 0.99 \\
\hline
\end{tabular}

Values are mean $\pm S D$.

RFs: $0.49 \pm 0.17 \mathrm{mmHg} / \mathrm{mL} / \mathrm{min}$; $\geq 3$ RFs: $0.50 \pm 0.12 ; P=0.43)$, or for PWV to the fingertip ( $<3$ RFs: $1661 \pm 449 \mathrm{~cm} / \mathrm{s} ; \geq 3$ RFs: $1641 \pm 510 \mathrm{~cm} / \mathrm{s} ; \quad P=0.70)$, or to the toe $(<3$ RFs: $1312 \pm 323 \mathrm{~cm} / \mathrm{s} ; \geq 3$ RFs: $1417 \pm 322 \mathrm{~cm} / \mathrm{s} ; P=0.23)$.

\section{EFFECT OF ANTI-HYPERTENSIVE AND ANTI-CHOLESTEROL MEDICATIONS}

The data were re-evaluated to display the significant effects of anti-hypertensive medication or statin use (Tables 4 and 5, respectively). The following data reflect those values that were statistically significant, or demonstrated strong statistical trends, following analysis of medication effects.
Participants taking anti-hypertensive medication had lower predicted aerobic capacity $\left(V_{\mathrm{O}_{2} \max } ; P=0.01\right)$, higher HDL cholesterol $(P=0.02)$, lower triglycerides $(P=0.02)$, higher heart rate $(P=0.001)$, lower diastolic pressure $(P=0.03)$, lower calculated left ventricular mass $(P=0.02)$, thinner interventricular septal wall $(P=0.003)$, thinner left ventricular posterior wall $(P=0.02)$, shorter LVPEP $(P=0.007)$, and a less distensible carotid artery $(P=0.02$; Table 4).

Participants taking statins tended to be older $(P=0.06)$ and have a higher Framingham risk score $(P=0.06)$, lower HDL cholesterol $(P=0.07)$, higher HOMA-IR $(P=0.07)$, and lower forearm vascular resistance $(P=0.09)$. Participants taking 
Table 4 | Effects of anti-hypertension medication.

\begin{tabular}{|c|c|c|c|}
\hline & $\begin{array}{l}\text { No anti- } \\
\text { hypertension } \\
\text { medication }\end{array}$ & $\begin{array}{l}\text { Anti- } \\
\text { hypertension } \\
\text { medication }\end{array}$ & $P$-values \\
\hline $\begin{array}{l}\text { Predicted } V_{\mathrm{O}_{2}} \max \\
(\mathrm{mL} / \mathrm{kg} / \mathrm{min})\end{array}$ & $33 \pm 6$ & $28 \pm 6$ & 0.01 \\
\hline $\begin{array}{l}\text { HDL Cholesterol } \\
\text { (mmol/L) }\end{array}$ & $1.17 \pm 0.34$ & $1.19 \pm 0.28$ & 0.02 \\
\hline Triglycerides (mmol/L) & $1.6 \pm 0.7$ & $1.4 \pm 0.7$ & 0.02 \\
\hline Heart rate (bpm) & $62 \pm 7.6$ & $70 \pm 10$ & 0.001 \\
\hline $\begin{array}{l}\text { Diastolic pressure } \\
(\mathrm{mmHg})\end{array}$ & $74 \pm 8$ & $74 \pm 9$ & 0.03 \\
\hline $\begin{array}{l}\text { Calculated left } \\
\text { ventricular mass (g) }\end{array}$ & $167 \pm 33$ & $149 \pm 40$ & 0.02 \\
\hline $\begin{array}{l}\text { Interventricular septal } \\
\text { wall thickness }(\mathrm{cm})\end{array}$ & $0.98 \pm 0.07$ & $0.93 \pm 0.11$ & 0.003 \\
\hline $\begin{array}{l}\text { Left ventricular } \\
\text { posterior wall } \\
\text { thickness }(\mathrm{cm})\end{array}$ & $0.95 \pm 0.08$ & $0.92 \pm 0.09$ & 0.02 \\
\hline $\begin{array}{l}\text { Left ventricle } \\
\text { pre-ejection period (ms) }\end{array}$ & $73 \pm 15$ & $64 \pm 12$ & 0.007 \\
\hline Carotid stiffness (cm) & $7.7 \pm 4.1$ & $9.5 \pm 3.5$ & 0.09 \\
\hline $\begin{array}{l}\text { Carotid distensibility } \\
\left(\mathrm{cm}^{*} \mathrm{mmHg}^{-1}\right)\end{array}$ & $0.0016 \pm 0.0007$ & $0.0012 \pm 0.0004$ & 0.02 \\
\hline
\end{tabular}

Values are mean $\pm S D$

statins had lower LDL cholesterol $(P=0.002)$, higher HbAlc $(P=0.01)$, and lower brachial artery inertia $(L ; P=0.03$; Table 5).

\section{DISCUSSION}

The current data suggest that the primary markers of cardiovascular dysfunction in MetS were centrally located in the heart. In particular, the lower $E / A$ ratio of $\sim 1.0$ suggests moderate diastolic dysfunction in those participants with MetS. The only indicator of altered peripheral vascular change with MetS was higher TPR, but with limited statistical power. However, forearm and carotid vascular resistance were not different between groups suggesting that visceral abdominal beds might be implicated in the higher TPR observed with MetS. There was no evidence that forearm or systemic PWV, carotid, or brachial conduit vessel stiffness, or the mechanics of the forearm vascular bed were affected by the degree of risk profile in the two groups. Therefore, vascular stiffness of the central and limb vascular beds was not affected by the MetS risk profile. Importantly, however, some vascular features normally attributed to MetS, such as carotid artery stiffness, were related to the presence of anti-hypertensive or statin medication. Whether the type, duration or intensity of therapy influenced the results is beyond the scope of this paper. Nevertheless, the presence of medication appears to be an important determinant of the vascular impact of MetS. Hence, these data suggest that MetS may be associated with central changes in the left ventricle and a modest increase in resistance of some non-limb segments of the vasculature. In contrast, some changes that have been previously attributed to MetS were more strongly related to medication
A

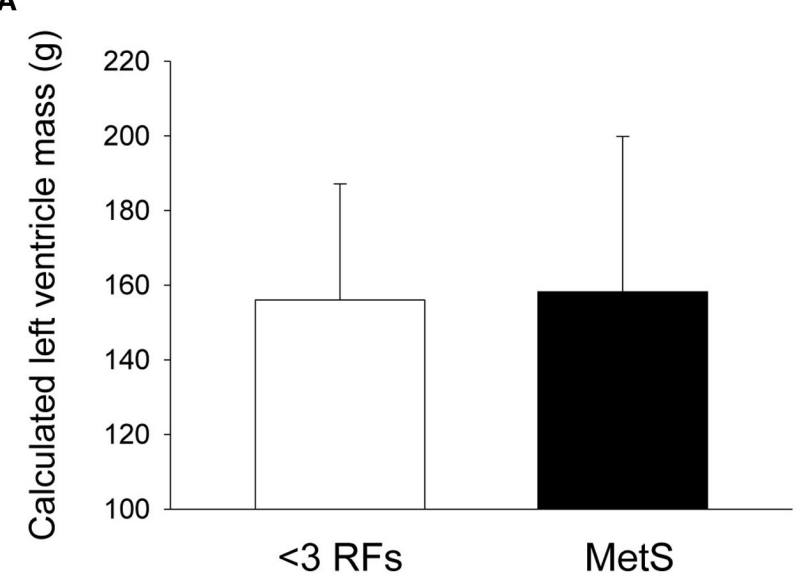

B

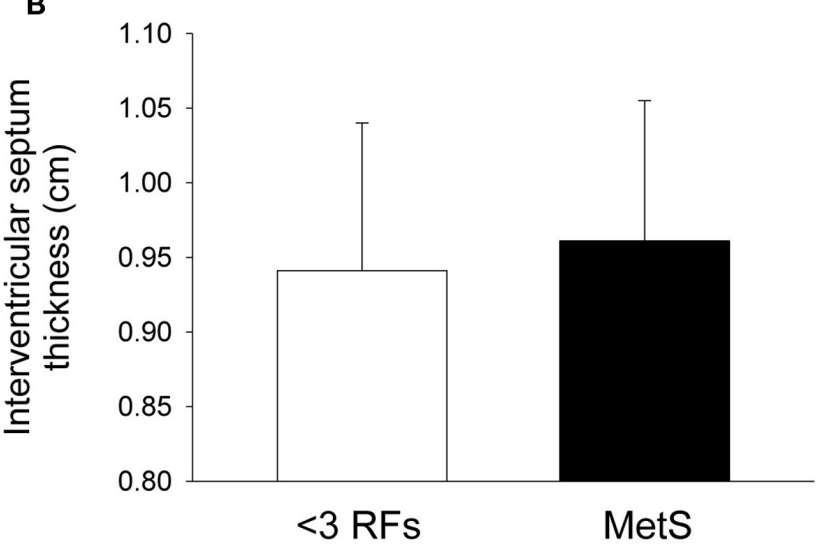

C

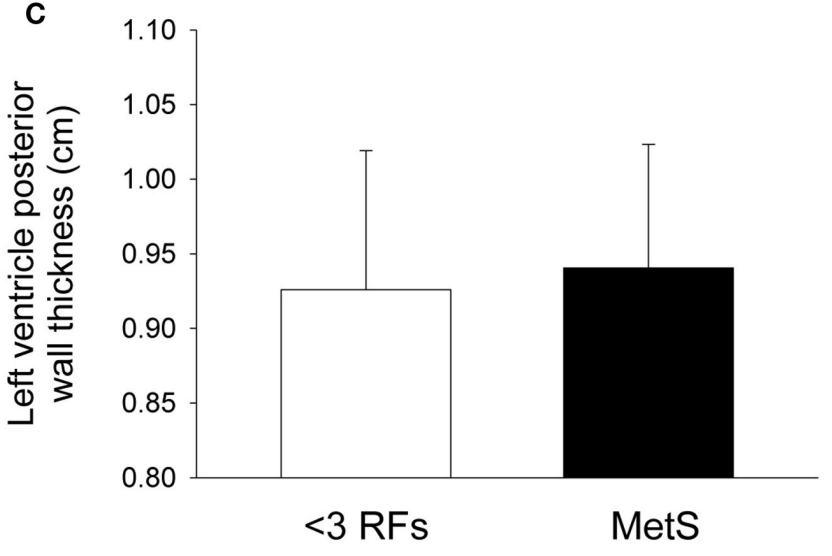

FIGURE 1 | Indices of heart size in individuals with metabolic syndrome (MetS). After adjustment for statin and blood pressure medication use, compared with individuals with less than three risk factors for cardiovscular disease ( $<3$ RFs) participants with MetS displayed no differences in (A) left ventricle mass $(P=0.49)$, (B) interventricular septal wall thickness $(P=0.12)$, or $(\mathbf{C})$ left ventricular posterior wall thickness $(P=0.17)$. There were significant effects of anti-hypertension medication use and statin use in all variables (see Tables 4 and $\mathbf{5}$ ). Values are mean $\pm S D$. Corresponding $\mathrm{SE}$ values are (A) $6.0 \mathrm{~g}$ (<3 RFs) and $6.3 \mathrm{~g}$ (MetS); (B) $0.02 \mathrm{~cm}(<3 \mathrm{RFs})$ and $0.01 \mathrm{~cm}$ (MetS); (C) $0.02 \mathrm{~cm}$ (<3 RFs) and $0.01 \mathrm{~cm}$ (MetS). 


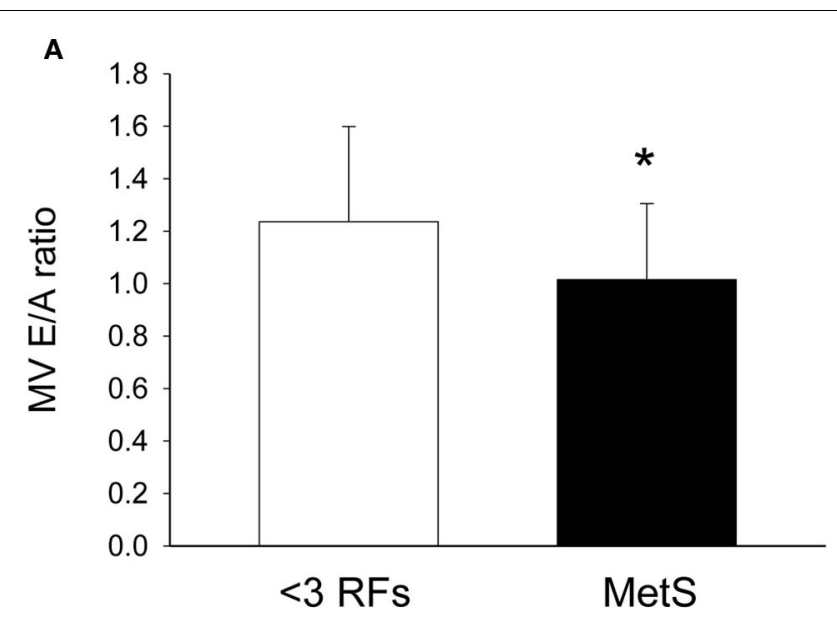

B

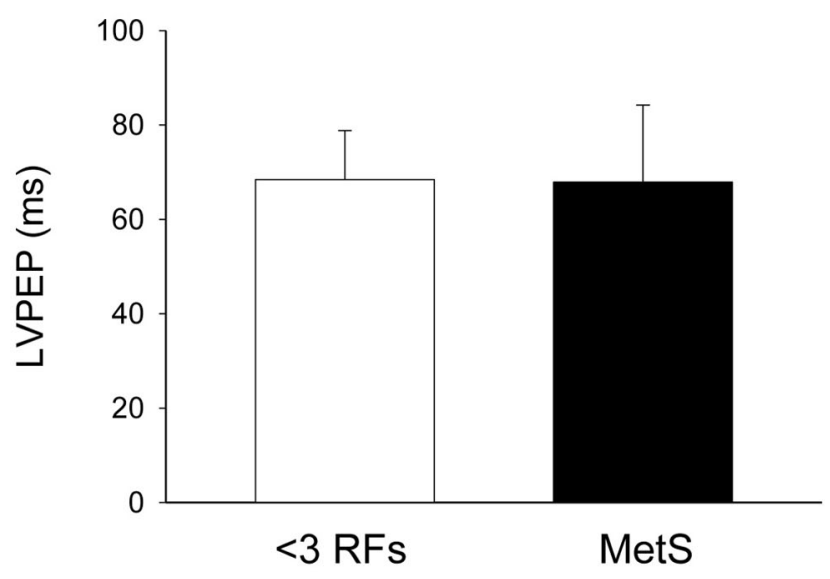

FIGURE 2 | Echocardiography of individuals with metabolic syndrome (MetS). After adjustment for statin and blood pressure medication use, compared with individuals with less than three risk factors for cardiovscular disease (<3 RFs) participants with MetS displayed (A) lower mitral valve $E / A$ ratio (MV E/A ratio; an indicator of left ventricle relaxation; $P=0.03$ ) and (B) no difference in left ventricular pre-ejection period (LVPEP; $P=0.27$ ). There were significant effects of anti-hypertension medication use on LVPEP (see Table 4). Values are mean \pm SD. Corresponding SE values are (A) 0.07 (<3 RFs) and 0.04 (MetS); (B) $2.0 \mathrm{~ms}(<3 \mathrm{RFs})$ and $2.6 \mathrm{~ms}$ (MetS).

use in the current analysis. Thus, it appears that the trajectory of cardiovascular dysregulation in MetS begins in the heart and not in limb vascular beds.

By definition, people with MetS exhibit at least three of the following RFs: elevated blood pressure, waist circumference, triglycerides, blood glucose, or reduced HDL cholesterol (Grundy et al., 2004). Higher insulin and HOMA values are also observed in MetS (Vonbank et al., 2011). After adjusting for anti-hypertensive medication and statin use significantly higher BMI, lower HDL cholesterol, higher triglycerides, and higher HbAlc (an indicator of long-term plasma glucose) were observed in the MetS group with $>3$ RFs in this study. The differences in HDL cholesterol and triglycerides reinforce the group classification of these individuals.
Whereas correcting for anti-hypertensive or statin medications exposed important risk factor profiles in our groups, this approach also highlighted the observation of relatively few cardiovascular consequences of increasing risk of MetS. Nonetheless, one outcome that was not altered by the correction for medications was lower mitral valve $E / A$ ratio. This finding supports earlier reports (Gong et al., 2009; Turhan et al., 2009; Hwang et al., 2011). The $E / A$ value of $\sim 1.0$ suggests modest diastolic dysfunction that can occur in the absence of any detectable change in systolic function such as ejection fraction or stroke volume. Nonetheless, a lowered $E / A$ ratio is commonly associated with a greater risk of developing congestive heart failure (Arnlov et al., 2004) and this has raised emphasis for early treatment in MetS patients with concomitant left ventricular diastolic dysfunction (Dinh et al., 2011). The lower $E / A$ ratio was affected by a higher $A$ velocity $(P=0.06)$. The mitral $A$-wave velocity reflects the LA-LV pressure gradient during late diastole, which is affected by LV compliance and LA contractile function. Thus, from a mechanistic perspective, the higher $A$ velocity could be a result of left atrial enlargement that has been observed with MetS (Cuspidi et al., 2005).

It is recognized that the determination of left ventricular diastolic dysfunction is best determined with a more comprehensive analysis approach (Goncalves et al., 2010) in contrast to the singular measurement of transmitral flow. The $E / E^{\prime}$ values were within the normal range for all individuals in the current study suggesting that left ventricular relaxation rate was not affected by the risk factor profile. Overall, the marker of mitral value filling dynamics suggests the need for a deeper and focused examination of left ventricular function in MetS as an early marker of cardiac disease. Ultrasound-based measurements are non-invasive and appropriate for large scale studies. However, echocardiographybased measures may actually underestimate the degree of diastolic dysfunction (Zile et al., 2004).

Previously, it has been reported that carotid artery distensibility was diminished in individuals with MetS (Ferreira et al., 2005). Whereas the values of carotid artery distensibility observed here are similar to those reported earlier in non-medicated MetS patients (Aizawa et al., 2009), there was no difference between groups following adjustment for medications (Figure 3C). Unfortunately, it is difficult to make direct comparisons with existing literature on this topic due to variations in the sample under investigation. For example, Ferreira et al. (2005) investigated a group of relatively young (36 years old) and unmedicated individuals and observed increased stiffness of the carotid artery. Della-Morte et al. (2010) used medicated participants and statistically adjusted for medication use and still found higher carotid stiffness in participants with MetS. However, the participants in the Della-Mort et al. study were approximately 6 years older than ours with a majority of the participants being of Hispanic or Black race/ethnicity $(\sim 80 \%)$. This is important because middle-aged Black men demonstrate greater carotid stiffness than caucasian men (Din-Dzietham et al., 2004). Furthermore, Karlamangla et al. (2010) found that USborn Black and Hispanic men have a higher metabolic risk in comparison to a White population. These findings suggest that age, ethnicity, and pharmacological treatment are important factors to consider when evaluating the association between altered vascular behavior and MetS. 


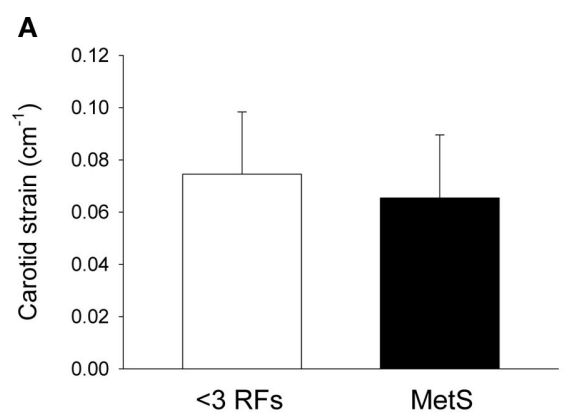

C

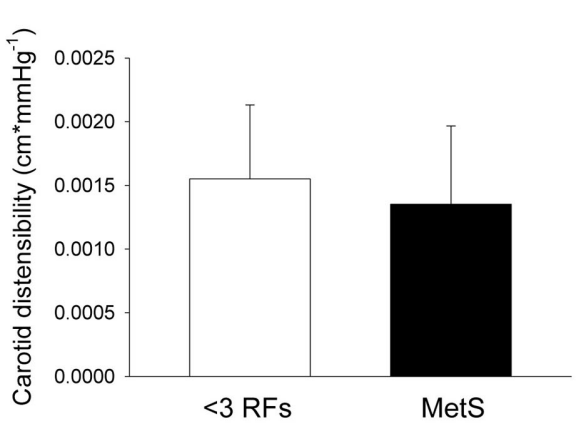

FIGURE 3 | Carotid artery dynamics of individuals with metabolic syndrome (MetS). After adjustment for statin and blood pressure medication use, compared with individuals with less than three risk factors for cardiovascular disease ( $<3 \mathrm{RFs}$ ) participants with MetS were not different in carotid artery $(\mathbf{A})$ strain $(P=0.34)$, (B) stiffness $(P=0.40),(\mathbf{C})$ distensibility $(P=0.75)$, and (D) elastic modulus $(P=0.23)$. There was a trend for an effect

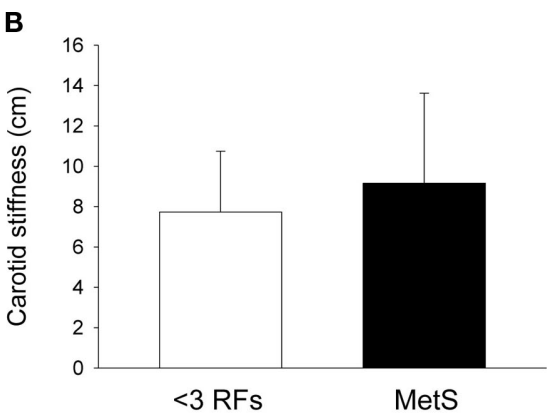

D

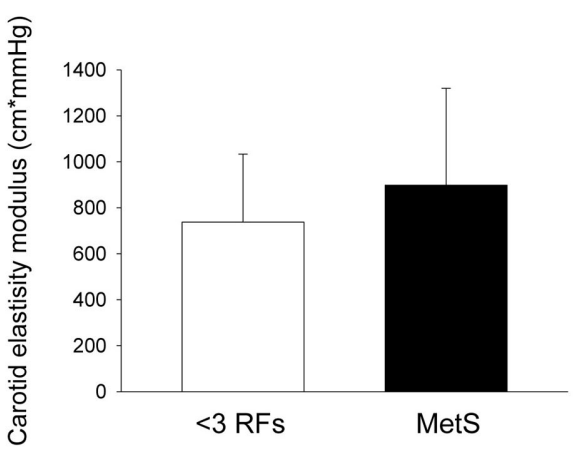

of anti-hypertension medication on carotid stiffness (see Table 4). There was a significant effect of anti-hypertension medication use on carotid distensibility (see Table 4). Values are mean \pm SD. Corresponding SE values are (A) $0.005 \mathrm{~cm}^{-1}(<3 \mathrm{RFs})$ and $0.004 \mathrm{~cm}^{-1}$ (MetS); (B) $0.6 \mathrm{~cm}(<3 \mathrm{RFs})$ and $0.07 \mathrm{~cm}$ (MetS); (C) $0.0001 \mathrm{~cm}^{*} \mathrm{mmHg}^{-1}$ (<3 RFs) and $0.0001 \mathrm{~cm}^{*} \mathrm{mmHg}^{-1}$ (MetS); (D) $57 \mathrm{~cm}^{*} \mathrm{mmHg}(<3 \mathrm{RFs})$ and $67 \mathrm{~cm}^{*} \mathrm{mmHg}$ (MetS).
It is not clear how anti-hypertensive medications are affecting the carotid artery. In the current study the unexpected finding was that anti-hypertensive treatment was associated with lowered carotid artery distensibility. While this observation appears paradoxical it may reflect the fact that patients on anti-hypertensive agents have hypertension, although they were pharmacologically controlled in this sample.

No differences were observed in PWV in participants with MetS compared to those with fewer RFs. These observations are in contrast to other reports that have found higher PWV in the large arteries of participants with MetS (Li et al., 2005; Nakanishi et al., 2005; Kim, 2006; Miyaki et al., 2006; Ghiadoni et al., 2008; Lin et al., 2009). Two of these earlier investigations recruited participants that were not medicated for hypertension or dyslipidemia (Kim, 2006; Ghiadoni et al., 2008) whereas four other investigations recruited participants taking medications, but did not adjust for them (Li et al., 2005; Nakanishi et al., 2005; Miyaki et al., 2006; Lin et al., 2009). Controlling for hypertensive medications is important as Ghiadoni et al. (2008) observed that higher blood pressure was the only risk factor of MetS that is associated with higher PWV. Further, elevated blood pressure will independently reduce vascular distensibility by moving the vascular segment to a stiffer portion of the volume-pressure relationship.

In the current study higher TPR was observed in participants with MetS compared to those with fewer RFs. The mechanisms of heightened vascular contractile state in MetS may be related to a dysfunctional contractile state, such as that induced by abnormal nitric oxide production (Song et al., 2006) and/or to a remodeled vascular system with smaller lumen. However, the lack of changes in vascular stiffness would argue against a remodeled vascular bed. The site of the observed increased vascular tone is not known. Our observations suggest that the higher TPR in MetS was not due to changes in the brachial vascular bed or the carotid system. Therefore, other vascular beds could play a role. To our knowledge, there are no data examining the effect of MetS or associated pharmacology on the contractile behavior of abdominal vascular beds which can exert a large influence on total vascular resistance. Nonetheless, the effect was modest with limited statistical power and must be interpreted cautiously.

The mechanism underlying elevated TPR in MetS could also reflect a reflexive sympathetic neural effect as a consequence of reduced cardiac output. Koivistoinen et al. (2010) found that MetS in people aged 30-45 was associated with a higher systemic vascular resistance index but also a lower stroke volume index. However, no change in stroke volume or cardiac output index was observed in the current study. Our adjustment for anti-hypertensive or statin medications could account for the discrepancy between our study and the report of Koivistoinen et al. (2010). For example, in unmedicated participants with MetS, Mule et al. (2007) observed no difference in stroke volume index. It is acknowledged, however, 
A

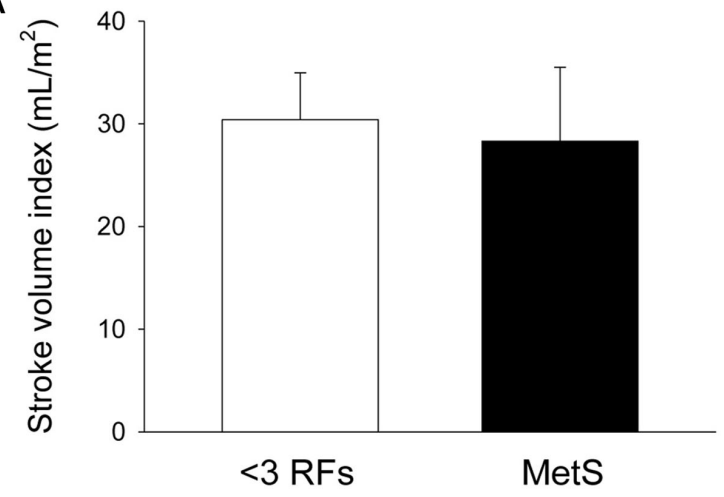

B

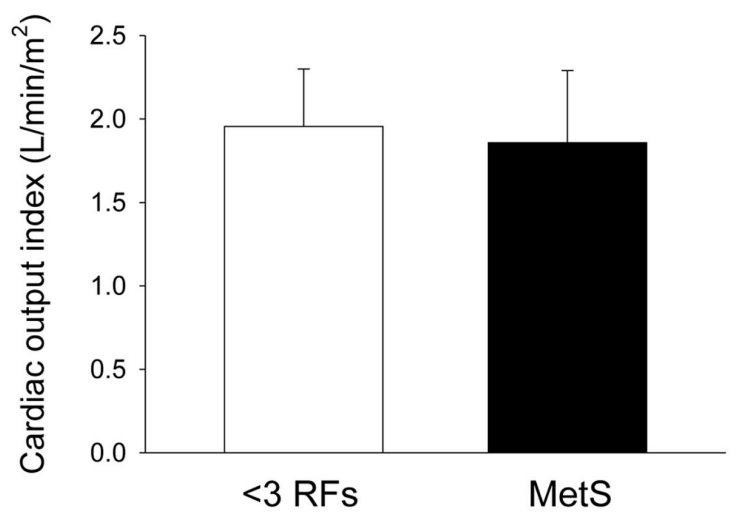

C

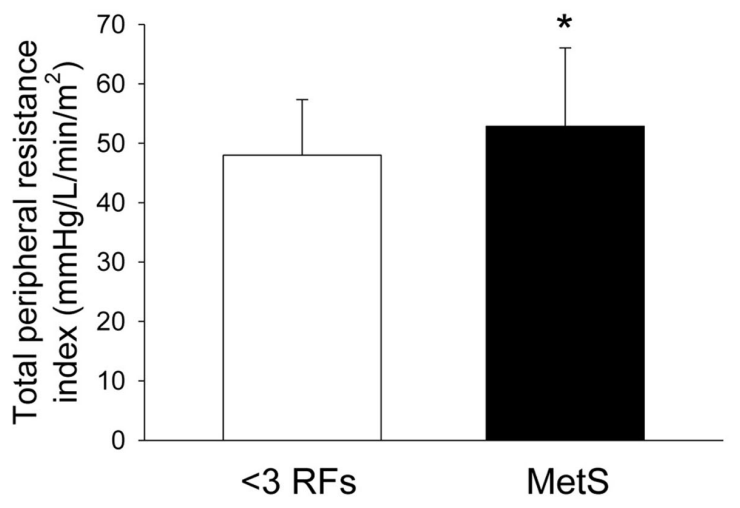

FIGURE 4 | Hemodynamics of individuals with metabolic syndrome (MetS). After adjustment for statin and anti-hypertensive medication use, compared with individuals with less than three risk factors for cardiovascular disease (<3 RFs) participants with MetS displayed (A) no difference in stroke volume index $(P=0.19)$; (B) no difference in cardiac output index $(P=0.34)$; and (C) higher total peripheral resistance index $(P=0.04)$. There were no significant effects of anti-hypertension medication use or statin use for all variables. Values are mean \pm SD. Corresponding SE values are (A) $0.9 \mathrm{~mL} / \mathrm{m}^{2}(<3 \mathrm{RFs})$ and $1.1 \mathrm{~mL} / \mathrm{m}^{2}$ (MetS); (B) $0.06 \mathrm{~L} / \mathrm{min} / \mathrm{m}^{2}(<3 \mathrm{RFs})$ and $0.07 \mathrm{~L} / \mathrm{min} / \mathrm{m}^{2}$ (MetS); (C) $1.8 \mathrm{mmHg} / \mathrm{L} / \mathrm{min} / \mathrm{m}^{2}(<3 \mathrm{RFs})$ and $2.0 \mathrm{mmHg} / \mathrm{L} / \mathrm{min} / \mathrm{m}^{2}$ (MetS).

that our observations of higher TPR in the MetS group were small and not accounted for clearly by either a reduced cardiac output
Table 5 | Effects of cholesterol medication (statins).

\begin{tabular}{|c|c|c|c|}
\hline & $\begin{array}{l}\text { No statin } \\
\text { adjustment }\end{array}$ & $\begin{array}{l}\text { Statin } \\
\text { adjustment }\end{array}$ & $P$-values \\
\hline Age & $57 \pm 8$ & $61 \pm 4$ & 0.06 \\
\hline $\begin{array}{l}\text { Framingham risk } \\
\text { score }(\%)\end{array}$ & $4.6 \pm 4.2$ & $7.2 \pm 5.5$ & 0.06 \\
\hline $\begin{array}{l}\text { LDL cholesterol } \\
\text { (mmol/L) }\end{array}$ & $3.0 \pm 0.9$ & $2.1 \pm 0.7$ & 0.002 \\
\hline $\begin{array}{l}\text { HDL cholesterol } \\
\text { (mmol/L) }\end{array}$ & $1.3 \pm 0.3$ & $1.1 \pm 0.2$ & 0.07 \\
\hline $\mathrm{HbA} 1 \mathrm{c}(\%)$ & $5.7 \pm 3.0$ & $6.0 \pm 3.7$ & 0.01 \\
\hline $\begin{array}{l}\text { HOMA-IR } \\
\left(\mathrm{pmol} / \mathrm{L}^{*} \mathrm{mmol} / \mathrm{L}\right)\end{array}$ & $3.0 \pm 2.2$ & $4.5 \pm 1.7$ & 0.07 \\
\hline $\begin{array}{l}\text { Calculated left } \\
\text { ventricular mass (g) }\end{array}$ & $153 \pm 35$ & $166 \pm 43$ & 0.07 \\
\hline $\mathrm{R}(\mathrm{mmHg} / \mathrm{mL} / \mathrm{min})$ & $6.5 \pm 4.3$ & $4.7 \pm 2.1$ & 0.09 \\
\hline $\mathrm{L}\left(\mathrm{mmHg} / \mathrm{mL} / \mathrm{min}^{2}\right)$ & $1.6 e^{-5} \pm 1.8 e^{-5}$ & $7.7 e^{-6} \pm 1.2 e^{-5}$ & 0.03 \\
\hline
\end{tabular}

Values are mean $\pm S D$. HOMA-IR, homeostatic model assessment for insulin resistance; $R$ and $L$ are resistance and inertia, respectively, from the lumped Windkessel model.

or elevated blood pressure but smaller contributions of both variables. Therefore, it is unclear whether vascular remodeling is the sole source of heightened TPR in this group.

Metabolic syndrome has deleterious effects on the autonomic nervous system. In particular, baroreflex control of heart rate is diminished. For example, Lindgren et al. (2006) found reduced cardiovagal baroreceptor sensitivity in unmedicated 70 year old participants with MetS compared to age-matched controls with zero RFs for MetS. Much of this reduction in cardiovagal baroreflex sensitivity may be related to body mass and/or composition, as reported by Beske et al. (2002) who, using a method of analysis that is analogous to the spontaneous slope assessment in this study, reported values of BRS in obese individuals that match those reported here for MetS participants with $<3$ RFs. All participants in the current study had a BMI greater than 30 units and are, thus, considered to be at least overweight if not obese. Thus, it is expected that all BRS values would be lower than control groups of the two studies reported above. To our knowledge, no other studies have examined BRS values within the range of RFs associated with MetS. Thus, while our data did not reach statistical significance, the cardiovagal baroreflex sensitivity in participants with $<3$ RFs appeared to be higher than in participants with MetS ( $<3$ RFs: $12.6 \pm 6.3 \mathrm{~ms} / \mathrm{mmHg} ; \geq 3 \mathrm{RFs}$ : $9.0 \pm 4.7 \mathrm{~ms} / \mathrm{mmHg} ; P=0.29)$ and this difference likely reflects the additional effect of other RFs.

\section{EFFECTS OF ANTI-HYPERTENSION MEDICATION}

It has been established that blood pressure medication lowers and stabilizes blood pressure in hypertensive individuals by reducing peripheral vasoconstriction or by increasing water extravasation from the plasma. Therefore, it is not surprising that we observed lower diastolic pressure in individuals taking anti-hypertensive medication. We also observed effects of anti-hypertension medication on predicted aerobic capacity 
( $\left.V_{\mathrm{O}_{2} \text { max }}\right)$, heart rate, HDL cholesterol, triglycerides, left ventricle size indices, pre-ejection period, and carotid distensibility.

Most evidence points to a beneficial effect of anti-hypertension medication on exercise capacity (Abdulla et al., 2004; Akbulut et al., 2006). Therefore, the lower $V_{\mathrm{O}_{2} \max }$ in the participants taking blood pressure medication likely indicates a lower fitness level in these participants, perhaps due to a more sedentary lifestyle. This is also evident from the significantly higher resting heart rate observed in the medicated participants.

Associated with the use of anti-hypertension medication, we observed higher HDL, lower triglycerides, smaller left ventricle mass index, thinner left ventricle posterior walls, and thinner interventricular septal walls. These results match those of Su et al. (2000). The use of anti-hypertensive agents could result in the reversal of left ventricular hypertrophy by lowering of blood pressure and, thereby, afterload. The observed smaller left ventricle and reduced cardiac afterload in the present study could be responsible for the shorter left ventricle pre-ejection period that we and Dodek et al. (1975) found with blood pressure medication use. Furthermore, Hamada et al. (1990) found a positive correlation between left ventricle mass and pre-ejection period in participants with hypertension.

Spoelstra-de Man et al. (2006) also found lower left ventricular mass after anti-hypertensive drug treatment; however, at the same time they observed greater distensibility of the carotid artery which is contrary to our findings. It is possible that these inter-study differences are due to the cross-sectional nature of the current study versus the repeated measures design of their study which examined experimentally the effect of anti-hypertensive medication (i.e., the treatment of previously untreated participants).

\section{EFFECTS OF ANTI-DYSLIPIDEMIC MEDICATION (STATINS)}

Lipid medications, particularly statins, are designed to lower the amount of cholesterol in the body by inhibiting the function of HMG-CoA reductase which is known to play a fundamental role in cholesterol synthesis in the liver, hence the lower levels of LDL in patients using statins. We observed lower HDL, lower LDL, higher HbAlc, and higher HOMA-IR with statin use. Statin use has been shown to lower LDL in women with MetS (Guclu et al., 2004). However, contrary to our findings, the same study found that statin use also resulted in higher HDL, lower HbA1c, and lower HOMA. Our results also seem to be contradictory to those of Su et al. (2000) who found that statin use decreased cardiac hypertrophy (we observed a trend for greater left ventricular mass with statin use). The participants in our cross-sectional study with groups composed of both males and females had been medicated for at least 3 months prior to the study whereas Guclu et al. (2004) used a repeated measures design in the same women before and after statin use. Su et al. (2000) also used a repeated measures design and gave statins to previously unmedicated participants (all of their participants also had previously unmedicated hypertension

\section{REFERENCES}

Abdul-Ghani, M., Nawaf, G., Nawaf, F., Itzhak, B., Minuchin, O., and Vardi,

P. (2006). Increased prevalence of microvascular complications in type 2 diabetes patients with the metabolic syndrome. Isr. Med. Assoc. J. 8, 378-382.

and were given anti-hypertensive medication). Similar to a previous report (Neutel et al., 2007) we also observed that statin use increased with age in a Canadian population. Thus experimental design, age, and one's sex may play significant roles in the differences between studies. The increase in age and decrease in HDL observed in our study are the likely candidates for the higher Framingham Risk Score observed with statin use. Petrella et al. (2007) observed greater statin use in older participants with lower HDL.

We found decreased vascular resistance and inertia downstream of the brachial artery with statin use. Peripheral arteries are important in the control of vascular resistance, and statin use has been shown to increase endothelial function (as measured by flow-mediated dilation in the brachial artery) in participants with coronary artery disease (Jarvisalo et al., 1999) or at risk for Type 2 Diabetes (Economides et al., 2004). This greater endothelial function could help to explain the lower resistance downstream of the brachial artery in the current study. Similar to the use of antihypertension medication, changes that we have observed due to statin use could be due to the underlying disease states. Therefore, these observations need to be interpreted cautiously.

\section{SIGNIFICANCE AND PERSPECTIVES}

The purpose of this study was to investigate the effects of MetS on a broad range of markers for altered central cardiac versus peripheral vascular mechanics. We found both central and peripheral effects in the form of a lower mitral valve $E / A$ ratio and higher TPR in participants with more RFs. However, the groups could not be differentiated based on indices of vascular stiffness. We also investigated the effects of both anti-hypertension medication and statin use, both of which are common in older populations. The outcomes of this secondary analysis indicate that some changes which are typically attributed to MetS were strongly associated with the presence of anti-hypertensive (such as lower carotid distensibility or higher PWV) or statin (such as higher HbA1c and HOMA-IR) medications. Thus, the current findings suggest that cardiovascular changes due to MetS do not follow a peripheryto-central vascular trajectory. In contrast, this study reaffirmed the need to consider diastolic dysfunction as an early marker of cardiovascular decline in MetS patients.

\section{LIMITATIONS}

This study was a cross-sectional design with investigations in individuals with MetS of varying duration and degree. Follow-up studies would be required to determine the further progression of the current observations.

\section{ACKNOWLEDGMENTS}

This research was supported by the Canadian Institute for Health Research (Team Grant \#161975). The authors would like to acknowledge the technical assistance of Arlene Fleischauer and Patricia Scott for their assistance in the collection of blood and echocardiography, respectively. The authors would also like to thank Dr. Larry Stitt for statistical help.

Abdulla, J., Abildstrom, S. Z. Christensen, E., Kober, L., and Torp-Pedersen, C. (2004). A meta-analysis of the effect of angiotensin-converting enzyme inhibitors on functional capacity in patients with symptomatic left ventricular systolic dys- 
function. Eur. J. Heart Fail. 6, 927-935.

Aizawa, K., Shoemaker, J. K., Overend, T. J., and Petrella, R. J. (2009). Effects of lifestyle modification on central artery stiffness in metabolic syndrome subjects with pre-hypertension and/or prediabetes. Diabetes Res. Clin. Pract. 83, 249-256.

Akbulut, T., Akgoz, H., Dayi, S. U., Celik, S. E., Gurkan, U., and Tayyareci, G. (2006). Evaluation of enalapril+losartan treatment with cardiopulmonary exercise test in patients with left ventricular dysfunction. Angiology 57, 181-186.

Arnlov, J., Ingelsson, E., Riserus, U., Andren, B., and Lind, L. (2004). Myocardial performance index, a Doppler-derived index of global left ventricular function, predicts congestive heart failure in elderly men. Eur. Heart J. 25, 2220-2225.

Beske, S. D., Alvarez, G. E., Ballard, T. P., and Davy, K. P. (2002). Reduced cardiovagal baroreflex gain in visceral obesity: implications for the metabolic syndrome. Am. J. Physiol. Heart Circ. Physiol. 282, H630-H635.

Blaber, A. P., Yamamoto, Y., and Hughson, R. L. (1995). Methodology of spontaneous baroreflex relationship assessed by surrogate data analysis. Am. J. Physiol. 268, H1682-H1687.

Cull, C. A., Jensen, C. C., Retnakaran, R., and Holman, R. R. (2007). Impact of the metabolic syndrome on macrovascular and microvascular outcomes in type 2 diabetes mellitus: United Kingdom Prospective Diabetes Study 78. Circulation 116, 2119-2126.

Cuspidi, C., Meani, S., Fusi, V., Valerio, C., Catini, E., Sala, C., Sampieri, L., Magrini, F., and Zanchetti, A. (2005). Prevalence and correlates of left atrial enlargement in essential hypertension: role of ventricular geometry and the metabolic syndrome: the evaluation of target organ damage in hypertension study. J. Hypertens. 23, 875-882.

de Simone, G., Devereux, R. B., Ganau, A., Hahn, R. T., Saba, P. S., Mureddu, G. F., Roman, M. J., and Howard, B. V. (1996). Estimation of left ventricular chamber and stroke volume by limited M-mode echocardiography and validation by two-dimensional and Doppler echocardiography. Am. J. Cardiol. 78, 801-807.

Della-Morte, D., Gardener, H., Denaro, F., Boden-Albala, B., Elkind, M. S., Paik, M. C., Sacco, R. L., and Rundek, T. (2010). Metabolic syndrome increases carotid artery stiffness: the
Northern Manhattan Study. Int. J. Stroke 5, 138-144.

Din-Dzietham, R., Couper, D., Evans, G., Arnett, D. K., and Jones, D. W. (2004). Arterial stiffness is greater in African Americans than in whites: evidence from the Forsyth County, North Carolina, ARIC cohort. Am. J. Hypertens. 17, 304-313.

Dinh, W., Lankisch, M., Nickl, W., Gies, M., Scheyer, D., Kramer, F., Scheffold, T., Krahns, T., Sause, A., and Futh, R. (2011). Metabolic syndrome with or without diabetes contributes to left ventricular diastolic dysfunction. Acta Cardiol. 66, 167-174.

Dodek, A., Burg, J. R., and Kloster, F. R. (1975). Systolic time intervals in chronic hypertension: alterations and response to treatment. Chest 68 , 51-55.

Economides, P. A., Caselli, A., Tiani, E., Khaodhiar, L., Horton, E. S., and Veves, A. (2004). The effects of atorvastatin on endothelial function in diabetic patients and subjects at risk for type 2 diabetes. J. Clin. Endocrinol. Metab. 89, 740-747.

Ferreira, I., Henry, R. M., Twisk, J. W., van, M. W., Kemper, H. C., and Stehouwer, C. D. (2005). The metabolic syndrome, cardiopulmonary fitness, and subcutaneous trunk fat as independent determinants of arterial stiffness: the Amsterdam Growth and Health Longitudinal Study. Arch. Intern. Med. 165, 875-882.

Frisbee, J. C. (2005). Reduced nitric oxide bioavailability contributes to skeletal muscle microvessel rarefaction in the metabolic syndrome. Am. J. Physiol Regul. Integr. Comp. Physiol. 289, R307-R316.

Ghiadoni, L., Penno, G., Giannarelli, C., Plantinga, Y., Bernardini, M., Pucci, L., Miccoli, R., Taddei, S., Salvetti, A., and Del, P. S. (2008). Metabolic syndrome and vascular alterations in normotensive subjects at risk of diabetes mellitus. Hypertension 51, 440-445.

Goncalves, A., Almeida, P. B., Lourenco, P., Alvelos, M., Betrencourt, P., and Azevedo, A. (2010). Clinical significance of impaired relaxation pattern in middle-aged and elderly adults in the general population. Rev. Port. Cardiol. 29, 1799-1806.

Gong, H. P., Tan, H. W., Fang, N. N., Song, T., Li, S. H., Zhong, M., Zhang, W., and Zhang, Y. (2009). Impaired left ventricular systolic and diastolic function in patients with metabolic syndrome as assessed by strain and strain rate imaging. Diabetes Res. Clin. Pract. 83, 300-307.
Grassi, G., Seravalle, G., Brambilla, G., Facchetti, R., Bolla, G., Mozzi, E., and Mancia, G. (2010). Impact of the metabolic syndrome on subcutaneous microcirculation in obese patients. J. Hypertens. 28, 1708-1714.

Grundy, S. M., Brewer, H. B. Jr., Cleeman, J. I., Smith, S. C. Jr., and Lenfant, C. (2004). Definition of metabolic syndrome: report of the National Heart, Lung, and Blood Institute/American Heart Association conference on scientific issues related to definition. Circulation 109, 433-438.

Guclu, F., Ozmen, B., Hekimsoy, Z., and Kirmaz, C. (2004). Effects of a statin group drug, pravastatin, on the insulin resistance in patients with metabolic syndrome. Biomed. Pharmacother. 58, 614-618. doi:10.1016/j.biopha.2004.09.005

Hamada, M., Hiwada, K., and Kokubu, T. (1990). Clinical significance of systolic time intervals in hypertensive patients. Eur. Heart J. 11(Suppl. I), 105-113

Hwang, Y. C., Jee, J. H., Kang, M., Rhee, E. J., Sung, J., and Lee, M. K. (2011). Metabolic syndrome and insulin resistance are associated with abnormal left ventricular diastolic function and structure independent of blood pressure and fasting plasma glucose level. Int. J. Cardiol. doi: 10.1016/j.ijcard.2011.02.039

Ingelsson, E., Sullivan, L. M., Murabito, J. M., Fox, C. S., Benjamin, E. J., Polak, J. F., Meigs, J. B., Keyes, M. J., O’Donnell, C. J., Wang, T. J., D'Agostino, R. B. Sr., Wolf, P. A., and Vasan, R. S. (2007). Prevalence and prognostic impact of subclinical cardiovascular disease in individuals with the metabolic syndrome and diabetes. Diabetes 56, 1718-1726.

Jarvisalo, M. J., Toikka, J. O., Vasankari, T., Mikkola, J., Viikari, J. S., Hartiala, J. J., and Raitakari, O. T. (1999). HMG CoA reductase inhibitors are related to improved systemic endothelial function in coronary artery disease. Atherosclerosis 147, 237-242.

Karlamangla, A. S., Merkin, S. S., Crimmins, E. M., and Seeman, T. E. (2010). Socioeconomic and ethnic disparities in cardiovascular risk in the United States, 2001-2006. Ann. Epidemiol. 20, 617-628.

Kim, Y. K. (2006). Impact of the metabolic syndrome and its components on pulse wave velocity. Korean J. Intern. Med. 21, 109-115.

Koivistoinen, T., Aatola, H., HutriKahonen, N., Juonala, M., Viikari, J. S., Laitinen, T., Taittonen, L.,
Lehtimaki, T., Koobi, T., Raitakari, O. T., and Kahonen, M. (2010). Systemic hemodynamics in young adults with the metabolic syndrome: the Cardiovascular Risk in Young Finns Study. Ann. Med. 42, 612-621. Kraemer-Aguiar, L. G., Laflor, C. M., and Bouskela, E. (2008). Skin microcirculatory dysfunction is already present in normoglycemic subjects with metabolic syndrome. Metab. Clin. Exp. 57, 1740-1746.

Li, S., Chen, W., Srinivasan, S. R., and Berenson, G. S. (2005). Influence of metabolic syndrome on arterial stiffness and its age-related change in young adults: the Bogalusa Heart Study. Atherosclerosis 180, 349-354.

Lin, W. Y., Lai, M. M., Li, C. I., Lin, C. C., Li, T. C., Chen, C. C., Lin, T., and Liu, C. S. (2009). In addition to insulin resistance and obesity, brachial-ankle pulse wave velocity is strongly associated with metabolic syndrome in Chinese a population-based study (Taichung Community Health Study, TCHS). J. Atheroscler. Thromb. 16, 105-112.

Lindgren, K., Hagelin, E., Hansen, N., and Lind, L. (2006). Baroreceptor sensitivity is impaired in elderly subjects with metabolic syndrome and insulin resistance. J. Hypertens. 24, 143-150.

Miyaki, K., Hara, A., Naito, M., Naito, T., and Nakayama, T. (2006). Two new criteria of the metabolic syndrome: prevalence and the association with brachial-ankle pulse wave velocity in Japanese male workers. $J$. Occup. Health 48, 134-140.

Mule, G., Nardi, E., Cottone, S., Cusimano, P., Palermo, A., Incalcaterra, F., Giandalia, M. E., and Cerasola, G. (2007). Impact of the metabolic syndrome on total arterial compliance in essential hypertension patients. $J$. Cardiometab. Syndr. 2, 84-90.

Nagueh, S. F., Appleton, C. P., Gillebert, T. C., Marino, P. N., Oh, J. K., Smiseth, O. A., Waggoner, A. D., Flachskampf, F. A., Pellikka, P. A., and Evangelista, A. (2009). Recommendations for the evaluation of left ventricular diastolic function by echocardiography. J. Am. Soc. Echocardiogr. 22, 107-133.

Nakanishi, N., Shiraishi, T., and Wada, M. (2005). Brachial-ankle pulse wave velocity and metabolic syndrome in a Japanese population: the Minoh study. Hypertens. Res. 28, 125-131.

Neutel, C. I., Morrison, H., Campbell, N. R., and de Groh, M. (2007). Statin use in Canadians: trends, determinants and persistence. Can. J. Public Health 98, 412-416. 
Parlow, J., Viale, J. P., Annat, G., Hughson, R., and Quintin, L. (1995). Spontaneous cardiac baroreflex in humans. Comparison with druginduced responses. Hypertension 25, 1058-1068.

Petrella, R. J., Koval, J. J., Cunningham, D. A., and Paterson, D. H. (2001). A self-paced step test to predict aerobic fitness in older adults in the primary care clinic. J. Am. Geriatr. Soc. 49, 632-638.

Petrella, R. J., Merikle, E., and Jones, J. (2007). Prevalence and treatment of dyslipidemia in Canadian primary care: a retrospective cohort analysis. Clin. Ther. 29, 742-750.

Song, D., Hutchings, S. R., and Pang, C. C. (2006). Impaired in vivo venous constriction in conscious obese Zucker rats with metabolic syndrome. Naunyn Schmiedebergs Arch. Pharmacol. 373, 451-456.

Spoelstra-de Man, A. M., van Ittersum, F. J., Schram, M. T., Kamp, O., van Dijk, R. A., Ijzerman, R. G., Twisk, J. W., Brouwer, C. B., and Stehouwer, C. D. (2006). Aggressive antihypertensive strategies based on hydrochlorothiazide, candesartan or lisinopril decrease left ventricular mass and improve arterial compliance in patients with type II diabetes mellitus and hypertension. J. Hum. Hypertens. 20, 599-611.

Stokes, K. Y., and Granger, D. N. (2005). The microcirculation: a motor for the systemic inflammatory response and large vessel disease induced by hypercholesterolaemia? J. Physiol. 562, 647-653.

Struijker-Boudier, H. A., Rosei, A. E., Bruneval, P., Camici, P. G., Christ, F., Henrion, D., Levy, B. I., Pries, A., and Vanoverschelde, J. L. (2007). Evaluation of the microcirculation in hypertension and cardiovascular disease. Eur. Heart J. 28, 2834-2840.

$\mathrm{Su}$, S. F., Hsiao, C. L., Chu, C. W., Lee, B. C., and Lee, T. M. (2000). Effects of pravastatin on left ventricular mass in patients with hyperlipidemia and essential hypertension. Am. J. Cardiol. 86, 514-518.

Tsuchikura, S., Shoji, T., Kimoto, E., Shinohara, K., Hatsuda, S., Koyama,
H., Emoto, M., and Nishizawa, Y. (2010). Central versus peripheral arterial stiffness in association with coronary, cerebral and peripheral arterial disease. Atherosclerosis 211 , 480-485.

Turhan, H., Yasar, A. S., Yagmur, J., Kurtoglu, E., and Yetkin, E. (2009). The impact of metabolic syndrome on left ventricular function: evaluated by using the index of myocardial performance. Int. J. Cardiol. 132, 382-386.

Vonbank, A., Saely, C. H., Rein, P., Beer, S., Breuss, J., Boehnel, C., and Drexel, H. (2011). Insulin resistance is associated with the metabolic syndrome and is not directly linked to coronary artery disease. Clin. Chim. Acta 412, 1003-1007.

Zamir, M., Goswami, R., Salzer, D., and Shoemaker, J. K. (2007). Role of vascular bed compliance in vasomotor control in human skeletal muscle. Exp. Physiol. 92, 841-848.

Zile, M. R., Baicu, C. F., and Gaasch, W. H. (2004). Diastolic heart failure abnormalities in active relaxation and passive stiffness of the left ventricle. N. Engl. J. Med. 350, 1953-1959.

Conflict of Interest Statement: The authors declare that the research was conducted in the absence of any commercial or financial relationships that could be construed as a potential conflict of interest.

Received: 12 October 2011; accepted: 09 February 2012; published online: $27 \mathrm{Feb}$ ruary 2012.

Citation: Edgell H, Petrella RJ, Hodges GJ and Shoemaker JK (2012) Central versus peripheral cardiovascular risk in metabolic syndrome. Front. Physio. 3:38. doi 10.3389/fphys.2012.00038

This article was submitted to Frontiers in Clinical and Translational Physiology, a specialty of Frontiers in Physiology.

Copyright (c) 2012 Edgell, Petrella, Hodges and Shoemaker. This is an openaccess article distributed under the terms of the Creative Commons Attribution Non Commercial License, which permits non-commercial use, distribution, and reproduction in other forums, provided the original authors and source are credited. 